\title{
A HUMANIZAÇÃO NO SERVIÇO PRESTADO NA SAÚDE PÚBLICA
}

\section{ARTIGO ORIGINAL}

TEIXEIRA, Hélida Rodrigues¹, SALGADO, José Vitor Vieira²

TEIXEIRA, Hélida Rodrigues. SALGADO, José Vitor Vieira. A humanização no serviço prestado na saúde pública. Revista Científica Multidisciplinar Núcleo do Conhecimento. Ano: 06, Ed. 08, Vol. 01, pp. 177-193. Agosto 2021. ISSN: 24480959, Link de acesso: https://www.nucleodoconhecimento.com.br/saude/servico, DOI: 10.32749/nucleodoconhecimento.com.br/saude/servico

\section{RESUMO}

O Sistema Único de Saúde (SUS), teve seu surgimento após lutas pela democratização em meados de 1988, com objetivo de atender todos os cidadãos com um sistema de saúde pública e gratuita. Porém, começou a apresentar um sistema caótico, de violência diante do atendimento ao público, e diante destas reflexões e discussões surge a defesa do processo de humanização, com suas características complexas e subjetivas. Assim, destaca-se a Política Nacional da Humanização $(\mathrm{PNH})$, como um meio de promover o processo de humanização nos sistemas de saúde pública, com princípios éticos, respeito no ambiente hospitalar, na finalidade de estabelecer uma relação com os pacientes. Desse modo, a presente investigação é bibliográfica, descritiva e qualitativa na finalidade de corresponder ao objetivo de apresentar a importância da humanização nas práticas dos profissionais da saúde no sistema público. Assim, diante os objetivos expostos o trabalho tem como objetivo responder o seguinte questionamento: como promover o processo de humanização nas práticas dos profissionais da saúde? Contudo, diante os resultados obtidos, constata-se que é preciso conscientizar os profissionais contribuírem para o processo de humanização, refletindo os aspectos que envolvem

\footnotetext{
${ }^{1}$ Bacharelado em enfermagem - Unincor (Universidade Vale do Rio Verde)- Pós Graduação em Saúde da Família- Pós Graduação em Enfermagem do Trabalho- Pós Graduando em Gestão a saúde - Técnico de Enfermagem-Cefem-MG - Escola Estadual Padre Laerte Esperança de Oliveira.

${ }^{2}$ Orientador.
}

RC: 93397

Disponível em: https://www.nucleodoconhecimento.com.br/saude/servico 
o profissional da saúde e o paciente. É necessário que desenvolvam ações e processos humanizados, bem como compreender o paciente e suas necessidades.

Palavras-chave: SUS, Política Nacional da Humanização, humanização.

\section{INTRODUÇÃO}

O presente estudo, embasa-se em teorias que tratam sobre a humanização no atendimento da saúde pública. Desse modo, vale destacar sobre o Sistema Único de Saúde (SUS), surgiu por meio de lutas pela democratização em 1988. Seu objetivo é atender todos no sistema de saúde, sendo ele um direito de qualquer cidadão de maneira gratuita. Contudo, é um sistema que promove os princípios básico da responsabilidade do Estado a qual está previsto na Constituição Federal de 1988.

Sendo assim, atualmente o sistema de saúde passa por um momento de reflexão, a qual se encontra diversas discussões no que diz a respeito da humanização. Nesse sentido está presente no cotidiano da saúde, casos de violência contra a população brasileira no momento de procura aos serviços de saúde. Assim, surge-se a humanização da saúde como elemento que irá contribuir para garantir os direitos das pessoas que buscam o sistema de saúde público.

Desse modo, nasce em 2003 a Política Nacional de Humanização, com o objetivo de atuar no SUS, práticas de atenção e gestão que efetive os princípios de um bom atendimento, valorizando o trabalho em equipe e cuidados entre os envolvidos. Porém, diante o sistema caótico, está presente a dificuldade da comunicação, a qual devem ser refletidos e repensados para aprimorar as ações dos profissionais da saúde diante o atendimento no sistema público.

O Programa Nacional de Humanização da Assistência Hospitalar (PNHAH) foi o primeiro programa governamental da Secretaria da Assistência à Saúde, do Ministério da Saúde, com duração entre os anos 2000 e 2002. Ele antecede e lança os pilares da constituição da Política Nacional de Humanização (PNH) de 2003 (AZEREDO; SCHAIBER, 2021)

Sendo assim, por meio de uma pesquisa bibliográfica, descritiva e de cunho qualitativa, com objetivo geral de apresentar a importância da humanização nas 
práticas dos profissionais da saúde no sistema de saúde público. Especificamente, os objetivos são entender o processo de humanização e seus conceitos; contextualizar a Política Nacional da Humanização (PNH); analisar a formação dos profissionais da saúde para a sua atuação no SUS. Diante os objetivos apresentados, partiu-se da seguinte questão norteadora: como promover o processo de humanização nas práticas dos profissionais da saúde?

Contudo, a pesquisa com sua finalidade de compreender o processo que contribui para o processo de humanização, diante a literatura, constata-se a necessidade de conscientização, preparação e capacitação aos profissionais da saúde, para que possa compreender o seu ambiente de trabalho e os pacientes que estarão envolvidos com suas necessidades de um atendimento digno e respeitoso.

\section{METODOLOGIA DA PESQUISA}

O presente estudo trata-se de uma pesquisa bibliográfica, descritiva de cunho qualitativa, seguindo aportes teóricos que abordam sobre a temática pesquisada. Assim, busca detalhar dados por meio de materiais que já foram publicados, a qual configura como uma revisão bibliográfica, sendo uma ótima maneira de coletar informações para concretizar este trabalho.

Assim, para entende melhor sobre pesquisa bibliográfica:

A pesquisa bibliográfica é desenvolvida a partir de material já elaborado, constituído principalmente de livros e artigos científicos. Embora em quase todos os estudos seja exigido algum tipo de trabalho desta natureza, há pesquisas desenvolvidas exclusivamente a partir de fontes bibliográficas (GIL, 2008, p. 50)

Sendo assim, para selecionar os materiais já elaborados, foi utilizado o mecanismo de busca Portal Periódico da CAPES (Coordenação de Aperfeiçoamento de Pessoal de Nível Superior) e Google Acadêmico, com as palavras-chaves: "humanização", "sistema de saúde pública", "enfermagem" e "SUS", combinações diferentes e variando os campos de busca. Foram coletados cinco materiais pertinentes que contribuíram para a investigação, publicados entre o período de 2015-2020. Na 
revisão de literatura, percebe-se umas certas quantidades de trabalhos científicos voltados a esse assunto. Nesse sentido, foi selecionado o trabalho de Silva (2020), Silva et al. (2021), Ferreira e Artman (2018), Lopes et al. (2015), Winzierl; Costa e Remon (2015).

Desse modo, a pesquisa propôs cumprir com a ciência por meio de um processo sistematizado, bem como estudo acadêmico para enriquecimento do conhecimento científico no que diz a respeito da humanização no sistema de saúde pública. Assim, buscou compreender o problema investigado em uma busca ilimitada, determinando hipóteses e teorias que explicam sobre o tema estabelecido.

Assim, apresenta-se um estudo qualitativo:

A pesquisa qualitativa responde a questões muito particulares. Ela se preocupa, nas ciências sociais, com um nível de realidade que não pode ser quantificado. Ou seja, ela trabalha com o universo de significados, motivos, aspirações, crenças, valores e atitudes, o que corresponde a um espaço mais profundo das relações, dos processos e dos fenômenos que não podem ser reduzidos à operacionalização de variáveis. (MINAYO, 2001, p.21-22)

Contudo, um estudo situado na área da saúde, a qual identificará conceitos e elementos necessários para buscar resultados dos objetivos propostos a qual tratam sobre o tema humanização de atendimentos do profissional da enfermagem, no sentido de esclarecer a importância do conhecimento para ações humanizadas no sistema de saúde pública.

\section{REVISÃO DA LITERATURA}

\subsection{HUMANIZAÇÃO E SEUS CONCEITOS}

A palavra humanização conforme as pesquisas, apontam ser uma atitude ou atividade complicada por não existir consenso diante suas características, subjetividade e complexidade. Na revisão de literatura, constata-se que a humanização é

[...] a cumplicidade, universalidade e solidariedade que o ser humano possui com os que o envolvem, sendo assim, a humanização na saúde refere-se ao

RC: 93397

Disponível em: https://www.nucleodoconhecimento.com.br/saude/servico 
profissional da saúde, aos seus pacientes, a sociedade, os profissionais entre si, cooperando e buscando, sempre, a dignidade humana na área da saúde (MORAIS, 2016, apud SILVA, 2020).

Nesse sentido, levando a humanização no sistema de saúde, apresenta-se que é tratar as pessoas com suas individualidades, com respeito e sem julgamento, preservando a autonomia e dignidade do ser humano. Assim, entende-se que são princípios éticos que devem ser levados em consideração em qualquer profissão, e no ambiente hospitalar necessita estabelecer uma relação com os pacientes de maneira coerente, princípio da dignidade humana e com seu direito.

Silva et al. (2021, p. 4), afirmam que humanizar é promover ao paciente estado positivo em maneira integral, contribuindo no seu corpo, mente e alma, e não focar somente na doença. Assim, é preciso considerar o emocional e capacidade de lidar com as diferenças, seja a respeito da financeira, religião, etnias. Um atendimento em base da humanização é propor a escuta do paciente, bem como sua compreensão diante o seu estado da saúde.

Ao longo do tempo, conta na literatura que as práticas de humanização foram discutidas e buscadas para promover melhor qualidade do cuidado ao usuário e dignidade do profissional da saúde. Ferreira e Artman (2018), apontam que, com a implementação do SUS, foram adotados diversos projetos de humanização por meio do governo, no primeiro instante para área materno-infantil. Desse modo, possuem uma visão diante a humanização, a qual visa a priorização da atenção e satisfação do usuário do sistema público.

A humanização prioriza inicialmente a qualidade da atenção e satisfação do usuário, e só posteriormente incorpora as questões referentes aos profissionais de saúde. Podemos afirmar que, independente de programas ou da política, sempre houve nichos na saúde onde a prática humanizada foi exercitada. (FERREIRA; ARTMAN, 2018, p.1438).

Nesse sentido, entende-se que já era presente a prática da humanização no meio das práticas dos profissionais da saúde. Para os autores, os conceitos de humanização estão relacionados com a integralidade do cuidado, um princípio que 
promove discussão e debate no objetivo de transformar as práticas e qualidade de cuidado.

Assim, de acordo com Lopes et al. (2015, p. 2377) humanizar é "oferecer atendimento de qualidade articulando os avanços tecnológicos com acolhimento, com melhoria dos ambientes da assistência e das condições de trabalho dos profissionais". Desse modo, conforme os autores, humanizar é resgatar o respeito do ser humano, além de aceitar o paciente e entender que é um indivíduo que possui diversos sentimentos. Sentimentos como medo, dor, dúvidas, inseguranças.

Lopes et al. (2015), apresentam que a humanização é um trabalho considerado multidisciplinar e interdisciplinar, pois, além de ampla e complexa, deve ser compreendida diante os pensamentos e atitudes que envolvem o usuário do sistema público. Entretanto, na literatura constata-se que os profissionais buscam pela excelência em seu atendimento, bem como a busca de aprimorar seu cuidado e suas técnicas baseados nos princípios humanísticos. Porém, para que esse processo ocorra de maneira humanística, deve relacionar com o estado físico e mental do profissional, pois, explica que dependendo da maneira negativa, cansaço, escassez, os funcionários podem desenvolver sua prática de forma desfavorável.

Conforme a pesquisa de Ferreira e Artman (2018), as entrevistas apresentaram o que os profissionais entendem sobre a humanização, apontando em seus resultados ideias centrais: a) o relacionamento entre os profissionais da saúde; b) um trabalho em rede para não deixar o paciente sem assistência; c) funcionário com boas condições para realizar seu trabalho com liberdade e outros pontos que facilitam o bem-estar na ação; d) disponibilidade para ouvir o paciente; e) considerar o humano como centro da atenção; f) acolher e tratar o paciente como ser humano; g) dar atenção e informação do que o paciente precisa; h) preocupar com o outro; i) dar o tratamento que gostaria de receber; j) não ter preconceito; k) ajudar ensinando de maneira adequada; I) ter uma visão sobre o paciente como um todo; m) adaptar o tratamento ao paciente; n) obter vínculo; o) olhar mais humanizado como um todo, incluindo o bem estar do paciente; p) ter um olhar multidisciplinar. 
Em resposta, a pesquisas dos autores apontam com a intenção de melhorar a qualidade da assistência e humanização, diante as práticas e sujeitos. Isto é, Ferreira e Artman (2018, p. 1445) apresentam a necessidade de melhorar a maneira de relacionar entre as pessoas, tanto com os usuários como os profissionais. Além disso, defendem uma gestão participação e a responsabilização ao meio, um trabalho realizado de maneira conjunta, favorecendo todos. Contudo, para incorporar a humanização, é preciso considerar como um componente orgânico, a qual promove a reflexão diante o papel dos profissionais da saúde, na qual são os autores estratégicos para construir um ambiente humanizado.

A pesquisa de Lopes et al. (2015), apresentam uma análise quali-quantitativa com objetivo de identificar o conceito de humanização sob perspectiva dos pacientes estudados. Assim, apresentam que a humanização ocorre por meio da interação do profissional, e isso depende de sua capacidade de mobilizar o paciente para que ele se sinta parte do processo. No entanto, ressaltam que a humanização é influenciada com as características das pessoas, com atitudes imparcial, e julgamentos, a qual devem ser evitados nesse processo partindo com respeito ao paciente e sua singularidade, intimidade, espaços, crenças e valores. Contudo, os profissionais na pesquisa apresentam a dificuldade que ocorrem no dia a dia hospitalar.

\subsection{A POLÍTICA NACIONAL DA HUMANIZAÇÃO}

A Política Nacional de Humanização (PNH), foi criada em 2003 com objetivo de adotar práticas de humanização no sistema público de saúde, isto é, no Sistema Único de Saúde (SUS). Enfatizaram promover práticas e ações com princípio humanizado, pois, no cotidiano do sistema público da saúde se encontravam em condições precária no atendimento, embora já houvesse princípios e iniciativas que incentivam a PNH. Contudo, conforme Ferreira e Artman (2018, p. 1438), essa política "reafirma a necessidade de se investir na qualidade do cuidado, e não apenas na expansão da rede e do acesso. Mattos1 ressalta que a humanização, ainda que não faça parte dos princípios fundamentais do SUS, é hoje central para as políticas de saúde. 
Nessa mesma linha de pensamento, Lopes et al. (2015, p. 2376) apresentam que o PNH surgiu com objetivo de melhorar a qualidade e a eficácia dos serviços prestados pelas instituições públicas do Brasil, bem como modificar o padrão de assistência para atender os pacientes do sistema público de saúde. Desse modo, destacam que por meio da "Portaria n881/GM de 2001, institui o Programa Nacional de Humanização da Assistência Hospitalar (PNHAH), que visa aprimorar as relações entre profissionais de saúde e usuários, dos profissionais entre si e do hospital com a comunidade".

Assim, a PNH foi lançada com princípios de valorizar toda prática e atenção, bem como aprimorar a produção de saúde, no intuito de fortalecer o trabalho da equipe profissional de saúde de modo que seja uma atuação cooperativa e solidária, junto com informação e comunicação, promovendo o protagonismo dos envolvidos. Além disso, constata-se em Silva (2020) que a política tem como objetivo valorizar o home como ser observado em seus atos na assistência à saúde e qualificação dos profissionais para atuar nos ambientes hospitalares, na finalidade de promover organização de tecnologias modernas, dinâmicas e solidárias.

Constata-se uma crítica diante o PNH, a qual Ferreira e Artman (2018), apresentam a necessidade de considerar as condições de trabalho do trabalhador da saúde, para contemplar a humanização pelos dois lados: usuário e profissional. Nesse sentido, os autores destacam que o documento desvaloriza os trabalhadores a qual ainda é presente no SUS, com a necessidade de promover melhorias em suas condições, considerado como um desafio da política. Contudo, a humanização é valorizar todos os sujeitos envolvidos no processo do sistema da saúde, usuários, trabalhados e gestores, e, os trabalhadores e usuários são envolvidos nos processos de saúde sendo aqueles que contemplará as ações que promoverá a melhoria.

Weinzierl; Costa e Remor (2015), destacam as diretrizes estabelecidas e organizadas com a responsabilidade do SUS, a qual devem ser seguidas conforme fazem parte do Humaniza SUS, em que defende diálogo entre todos (colaboradores, trabalhadores da saúde, população, administração) com a finalidade de uma gestão 
participativa; fortalecer os grupos e comissões com plano de trabalho; estimular práticas que utilizem os recursos de maneira adequada (insumo, medicamentos); reforçar o compromisso com diversas práticas terapêuticas; adequar o ambiente conforme a necessidade; participação ativa nas unidades de saúde; sistema de comunicação e protagonismo entre equipe e população; incentivo e valorização do trabalho em equipe; atividade de valorização e cuidados aos trabalhadores.

Desse modo, Silva (2020) aponta que o SUS contextualiza em um sistema caótico que dificulta a comunicação entre profissionais e usuários, a qual apresenta a dificuldade de um atendimento humanizado. Cita o Comitê Técnico de Humanização da Assistência Hospitalar, em que apresenta uma sugestão para solucionar o problema da seguinte forma: o usuário deve obter um atendimento e tratamento de maneira digna, solidário e acolhida em relação com o profissional. A qual é o resgate do valor da humanização.

O Comitê ainda afirma que se deve cuidar do usuário - humanização no atendimento público - e cuidar de quem cuida - é humanizar as condições de trabalho dos profissionais da saúde. O objetivo primordial do Programa de Humanização da saúde é trazer ao paciente e seus familiares um atendimento humano e com qualidade, o que poderá influenciar- lós a buscar cuidados com a saúde, é, também, trazer mais força aos profissionais pelos merecidos cuidados a eles garantidos (DELABARY, 2006, apud. SILVA, 2020 $\mathrm{s} / \mathrm{p})$.

Contudo, apresenta-se um resultado significativo diante o atendimento humanizado, no sentido de contribuir para o estado psicológico dos pacientes, deixando-os sem medo de morrer, ameniza a ansiedade e sua depressão. No entanto, percebe-se a importância deste processo de atendimento e sua funcionalidade de modo interdisciplinar.

Nesse sentido, ressalta-se que para que o processo de humanização ocorra é preciso conscientizar os profissionais da saúde e outros agentes participativos do processo ao atendimento no sistema público de saúde. Diante essa perspectiva, o próximo tópico embasará as concepções voltada à atuação dos profissionais da enfermagem no SUS, estabelecendo uma linha de raciocínio que contribua na compreensão no papel do profissional diante $o$ atendimento hospitalar. 


\subsection{A HUMANIZAÇÃO NA ATUAÇÃO DOS PROFISSIONAIS DA SAÚDE NO SISTEMA ÚNICO DE SAÚDE (SUS)}

Com a implantação do SUS, constata-se nas pesquisas que passaram por diferentes momentos, a qual foram modificados a priorização, bem como o princípio, estratégia e opções políticas. Desse modo, destaca-se a atenção e gestão do cuidado, na qual não indissociáveis para que o processo de trabalho seja de maneira transformadora diante as práticas entre os envolvidos. Conforme Ferreira e Artman (2018) esse processo é subjetivo, e caminha junto com a atenção e gestão do cuidado para produzir a saúde, porém, se faltar assistência entre os dois lados, provocará adoecimento. Contudo, é preciso refletir o papel do SUS nesse processo para que não ocorra um processo de maneira negativa.

O SUS não é um projeto estático, sofrendo constante modificação e deve sempre buscar novas soluções para dar conta da complexidade da saúde pública num país de dimensões continentais como o Brasil. Problematizar o papel do profissional de saúde na construção desta teia, considerando a integralidade do atendimento ao usuário, é fundamental para aperfeiçoar seu funcionamento. (FERREIRA; ARTMAN, 2018, p.1438)

Diante essa perspectiva, discutem que a humanização ocorre por meio da relação entre os autores (usuários, profissional da saúde e gestão), para ocorrer o impacto entre eles. O usuário deve receber um atendimento de qualidade junto com recursos disponíveis às tecnologias, no sentido de produzir o atendimento humanizado. A respeito disso, reflete o papel do profissional da saúde: boas condições de trabalho, atenção na gestão e prática de uma atenção de qualidade. Para tanto, os autores ressaltam a necessidade de discussão para que as modificações ocorram, um processo que envolve pessoas saudáveis aptos de produzir saúde maneira humanizada.

Além disso, destacam a importância da linguagem do profissional com o usuário, sendo ela de maneira menos técnica e paciente para atendê-los de maneira que entendam. Nesse sentido, destacam que "a linguagem utilizada deve ser compreendida por todos os participantes da conversa" (FERREIRA; ARTMAN, 2018, p.1448). Entretanto, entende-se que os profissionais devem obter um 
comportamento e ação comunicativo a partir de um compartilhamento de pretensões, discussões, acordo, entrando em consenso com o usuário.

Outro ponto importante a destacar é o trabalho de equipe, na qual apontam em sua pesquisa:

Os profissionais destacaram as condições de trabalho e a autonomia de profissionais e de pacientes, valorizando o saber de cada um. Apontaram, ainda, para a importância do trabalho em equipe e para os limites do trabalho em saúde na instituição considerando a necessidade de uma abordagem intersetorial e maior necessidade de inserção na rede (FERREIRA; ARTMAN, 2018, p.1448),

Desse modo, compreende-se que os profissionais não devem ser automatizados, embora os recursos tecnológicos dispostos possibilitem de maneira positiva na prática profissional. Contudo, afirmam que as assistências de enfermagem não devem ser automatizadas, sendo ela realizada junto com o paciente e sua admissão no ambiente hospitalar, oferecendo um acolhimento com sistema de informação educativas, cientificar e humanizadas para obter um cuidado qualificado. Assim, diante a literatura, afirmam que a assistência e/ou o cuidado se constitui na essência da enfermagem, o qual compete ao enfermeiro reconhecer as peculiaridades de cada pessoa por ele atendida e adaptar o cuidado, ou seja, fornece um cuidado individualizado, integral e humanizado (LOPES et al., 2015, p. 2380).

Diante disso, entende-se que o profissional deve conscientizar e refletir que cada sujeito que precisará do atendimento público, possui suas individualidades, a qual precisam ser respeitadas, conforme foi citado nessa pesquisa. Contudo, apresentase também a necessidade de obter uma interação entre paciente e equipe de enfermagem para estabelecer um vínculo afetivo e de confiança. Contudo, essa prática irá possibilitar e promover a consciência de cuidado com o outro de qualidade, por meio de um atendimento acolhedor e ativo do cuidador, em que constitui em uma relação de confiança, consciência de emoções que irão melhorar no tratamento.

Portanto, o carinho, a simpatia, a compreensão do momento em que os pacientes se encontram, o respeito e a qualidade no atendimento são fatores 
que facilitam a humanização da assistência. Por outro lado, temos que o mau humor dos profissionais, o barulho, a interrupção do sono e o excesso de idas ao quarto do paciente constituem nos fatores negativos relatados pelos pacientes (LOPES et al., 2015, p. 2382)

A partir dessa concepção que reflete nas condições de trabalho do profissional, a qual deve ser analisado e refletido para promover as práticas humanizadas com o paciente. Desse modo, é preciso assumir o comportamento humanizado, considerando o paciente como um ser humano que possui sentimentos e que no momento que se encontra hospitalizado, está vulnerável e que precisa ser compreendido para a promoção de cuidados e respeito por meio de valores éticos que garantam sua condição de sujeito social.

Conforme a pesquisa de Lopes et al. (2015), embasam a situação e prática humanizadas com pacientes, crianças com câncer, destacando a estrutura do hospital e os limites presente no ambiente hospitalar. Nesse sentido, apresentam as condições de trabalho do profissional como um dos pontos que interfere na prática de humanização, a falta de um ambiente infantil aconchegante para que promova um ambiente que deixem as crianças seguras na realização do tratamento. Nessa linha de pensamento, entende-se a necessidade de avaliar o ambiente que será acolhedor ao paciente, sendo ele aconchegantes em busca de promover segurança e calma aos cuidados do paciente.

Segundo relatos de familiares de pacientes, estudo retrata que a realização de melhorias na infraestrutura hospitalar a fim de proporcionar mais privacidade e conforto durante o processo de internação na instituição, constitui-se numa possibilidade para que ocorra um atendimento humanizado e digno (LOPES et al., 2015, p.2383)

Assim, entende-se que são fatores que contribuem para que o processo de humanização ocorra, pois, as condições físicas e os recursos são fatores determinantes conforme a pesquisa dos autores. Porém, aponta-se que apesar dessas dificuldades enfrentadas pelos profissionais, não impede de organizar maneiras que ameniza os sofrimentos dos pacientes, uma vez que o processo se torna efetivo conforme o relacionamento e envolvimento entre os sujeitos envolvidos. 
Considera-se imprescindível a relação com os familiares, pois, no momento de medo, dor, situação de doenças, os profissionais também depararão com dificuldades, na comunicação entre familiares e profissionais, diante a jornada de trabalho das profissionais. Diante a pesquisa de Lopes et al. (2015), não há compreensão e colaboração dos familiares em relação aos cuidados, a qual dificultam 0 atendimento humanizado. Nesse sentido, há explicação, pois, os familiares se encontram ansiosos, estressados causados pelas doenças e problemas gerados do paciente, na qual o profissional de enfermagem deve compreender o cenário e contemplar as integralidades nas ações.

Assim, entende-se que para que o processo humanizado ocorre diversos fatores que podem interferir, sendo a relação com família um dos pontos que precisam ser refletidos e criar estratégias que lide com essa dificuldade. Pois, os autores explicam que a humanização pode ser "realizada mesmo em locais com precárias condições de trabalho, uma vez que são os próprios indivíduos que definem as estratégias para alcançá-la" (LOPES et al., 2015). Contudo, destacam que sempre existirá dificuldade, seja por conta de área física, financeiras ou de profissionais favoráveis que podem auxiliar no sofrimento do paciente.

Dessa maneira, há dificuldades diante a mentalidade, cansaço e estado físico do profissional., a qual desempenham um cuidado quanto a necessidades humanas dos pacientes. No entanto, diante a abordagem qualitativa, Lopes et al. (2015), apresentam a identificação dos fatores efetivos para a humanização e práticas. Concentraram nas questões de relações humanas no ambiente do trabalho, a qual faltam conhecimentos e preparação profissional para realizar o trabalho humanizado. Caracteriza-se que os profissionais realizam o trabalho de forma mecânica e deixam de lado os sentimentos e emoções do paciente e acaba demonstrando a falta de respeito nos momentos individuais em que dificulta o relacionamento entre eles.

Como soluções apresentam estratégias que podem utilizar para que o processo de humanização ocorra. Assim, os autores relatam que existe programas governamentais que determina que $o$ atendimento seja realizado de maneira 
humanizado, bem como pelos profissionais da saúde. Porém, estudos apontam que há uma procura elevada por parte da população por instituição de saúde a respeito do tratamento e postura de profissionais, a qual caracteriza-se como mecânica e tecnicista.

[...] o ato de cuidar perdeu a essência de seu significado, sendo que, para resgatá-lo, deve-se elaborar de forma ampla uma habilidade de reconhecer a pessoa como um ser integral. O cuidado precisa tornar-se uma atitude, um modo de pensar e agir reflexivos e não apenas como uma obrigação a se cumprir, contudo, o cuidar do outro é parte da natureza humana que deve ser resgatada (LOPES, et al., 2015, p.2385)

Assim, apresenta-se a necessidade de resgatar o ato de cuidar, é preciso que os profissionais da saúde obtenham uma escuta atenta um olhar em relação ao cuidado humanizado, refletindo a doença a qual o paciente está passando, compreendendoos e promovendo uma assistência diferenciada que contribuam na manutenção da emoção e cuidados.

A respeito do tratamento do câncer, Lopes et al. (2015) apontam algumas estratégias de acordo com seus estudos. Reflete na necessidade de permitir espaços para que as famílias relatem seus sentimentos, bem como sejam valorizados. Isto é, o profissional deve dar voz a aqueles que sofrem e identificar as áreas problemáticas e auxiliar na busca de resoluções de possíveis problemas relacionados ao tratamento. Assim, ressaltam a proposta de "elevar o desempenho de ações de autocuidado, de acordo com suas possibilidades" (LOPES, et al., 2015, p.2386). Contudo, existem inúmeras de ações de saúde necessária para a melhoria de cuidado na área psicológica, tento como disponibilidade a aceitação, criação e manutenção de um ambiente.

Lopes et al. (2015, p.2386) apresentam outras estratégias, a qual foram definidos pelos próprios pacientes: "os profissionais não devem dar importância ao desfecho do tratamento, mas que proporcionem o máximo que estiver ao seu alcance enquanto profissional de saúde". Como por exemplo: para as crianças, o profissional pode utilizar brinquedos, pois, são instrumentos infantis que auxilia em amenizar o 
sofrimento causado pela doença, bem como a situação em relação à família, animais de estimação, objetos pessoais, a qual são representação de sentimentos.

Nesse sentido, a responsabilidade do profissional de saúde é refletir sobre os sentimentos, angústias, promovendo uma relação de confiança entre paciente, família e profissionais, em base de respeito e carinho. Assim, vale ressaltar que a comunicação é imprescindível para que a ação ocorra de maneira necessária, e tenha um atendimento eficaz com as pessoas. Lopes et al. (2015) apontam também o avanço tecnológico em que contribuiu para tornar o atendimento eficaz, relacionando com a humanização, comunicação de maneira que obtenha ótimos resultados no atendimento, sendo ele de qualidade e garantia do bem-estar do paciente. Destacam também a importância da criatividade do profissional, pois é uma ferramenta que proporcionará um ambiente acolhedor e humano no envolvimento entre os pares.

\section{CONSIDERAÇÕES FINAIS}

Diante os objetivos expostos, apresenta-se que a humanização é uma palavra ampla, complexa e subjetiva na qual consiste no indivíduo que possui cumplicidade, solidariedade ao próximo, tratando-os conforme sua singularidade com respeito e sem julgamento. Considera-se o ser humanizado aquele que possui os princípios éticos e estabelece uma relação coerente e digna. Constata-se nas pesquisas que a humanização no sistema de saúde é o tratamento adequado que atende as expectativas do paciente e acolhe no momento de doença, no medo e insegurança.

Nesse sentido, considera-se imprescindível a adoção da humanização no sistema de saúde pública, na qual a Política Nacional da Humanização (PNH) contribui para a conscientização e mobilização dos profissionais do SUS atenderem os pacientes correspondendo aos seus direitos básicos como cidadão. Dessa forma, aponta-se que é preciso cuidar do usuário por meio de um atendimento humanizado, considerando o paciente e familiares com qualidade, na finalidade de obter um resultado significativo, contribuir para o estado psicológico do paciente, na manutenção de todos seus medos, inseguranças e ansiedade. 
Para tanto, o atendimento humanizado é interdisciplinar e multidisciplinar, pois, não se trata apenas da doença do paciente e sim como um todo, trabalhando com corpo, mente e alma considerando o paciente como um ser humano que possui sentimentos e emoções e naquele momento no hospital, provavelmente está vulnerável e com a necessidade de ser compreendido.

Dessa forma, os profissionais da enfermagem precisam desenvolver em suas ações o processo de humanizar o cuidado, trabalhando em equipe e buscando a aceitação em pacientes e seus familiares. Constata-se que, para humanizar de maneira mais facilitada é necessário compreender o paciente e suas necessidades por meio de um compromisso para que haja a humanização no atendimento. Contudo, percebese uma ampla literatura que embasa sobre o atendimento humanizado, bem como uma política que estabeleça para que ela aconteça. Entretanto é preciso aprimorar as práticas na formação do profissional da saúde, programas e capacitações para aprenderem a lidar com as dificuldades que surgirão ao longo de sua carreira.

\section{REFERÊNCIAS}

BRASIL. Ministério da Saúde (MS). Humaniza SUS: Política Nacional de Humanização: a humanização como eixo norteador das práticas de atenção e gestão em todas as instâncias do SUS. Brasília: MS; 2004.

BRASIL. Ministério da Saúde (MS). Humaniza SUS: Documento base para gestores e trabalhadores do SUS. $4^{\underline{a}}$ ed. Brasília: Editora do Ministério da Saúde; 2008.

FERREIRA, L. R.; E, ARTMAN. Discursos sobre humanização: profissionais e usuários em uma instituição complexa de saúde. (Artigo Schielo) Ciência \& Saúde Coletiva. 2018. p.1437-1450.Disponível em: https://www.scielo.br/j/csc/a/T7kRmxV7k8xCP4CgHMyxCDr/abstract/?lang=pt Acesso em: 25 de jun. 2021 
LOPES M, SILVA AC, FERREIRA AM, LINO AACF. Revisão narrativa sobre a humanização da assistência pela equipe de enfermagem na área oncológica. Rev. G\&amp;S [Internet]. $1^{\circ}$ de julho de 2015 [citado $28^{\circ}$ de junho de 2021]:Pag. 23732390. Disponível em: https://periodicos.unb.br/index.php/rgs/article/view/3115 Acesso em: 20 de jun. 2021

SILVA, R.A. Aplicação da humanização na saúde pública como aspecto de ponderação para decisões do judiciário como executor de políticas públicas. Artigo Online. OAB - Goiás. 2015. Disponível em: https://www.oabgo.org.br/esa/artigo-esa-goias/aplicacao-da-humanizacao-na-saudepublica-como-aspecto-de-ponderacao-para-decisoes-do-judiciario-como-executorde-politicas-publicas Acesso em: 21 de jun. 2021

SILVA, A.M.B; PEREIRA, M.C.; XAVIER, I.L.A.; LISBOA,A. F.M.; CARDOSO, Y.S.; ALCANTRA, T.R.; BEZERRA, K.F.A aplicabilidade da humanização no atendimento aos usuários do sistema único de saúde . Revista Eletrônica Acervo Saúde. Vol.13 2021.

WEINZIERL G, COSTA AM, REMOR CA. O perfil metodológico da produção científica sobre a política nacional de humanização do sistema único de saúde no cenário brasileiro desde a sua implantação em 2003. Rev. G\&amp;S [Internet]. $2^{\circ}$ de fevereiro de 2015 [citado 28을 de junho de 2021];6(1):pag. 451-471. Disponível em: https://periodicos.unb.br/index.php/rgs/article/view/2575 Acesso em: 24 de jun. 2021

Enviado: Novembro, 2020

Aprovado: Agosto, 2021. 